\section{ROAD RESEARCH}

THestion HE work of the Road Research Laboratory during the year ended March 31, 1939, is described in the annual report now obtainable*.

An important event recorded is the enlargement of the site of the Laboratory by sixteen acres, which has made possible the construction of a special skidding track 2,000 ft. long, providing facilities for investigating the causes of skidding under more favourable conditions than exist on the roads and forming a useful calibration surface for the several machines used by the Laboratory and by the Ministry of Transport. A notable feature of the report is its indication of the way in which the research work is now evolving from the purely laboratory stage into the large-scale practical demonstrations of the road engineer. Examples of this development which are to be found in the report include the full-scale tests on the use of acid to reduce the slipperiness of smooth concrete surfaces, the treatment by chemicals of icebound concrete surfaces and durability tests on bituminous and asphaltic binders. In co-operation with the Timber Development Association extensive practical trials are proceeding with the view of improving the skidding resistance of wood-block surfaces, while other large-scale investigations have led to a better design of cast-iron surfacing by which the sideway force coefficient has been increased from about $0 \cdot 25$ to $0 \cdot 45$.

Soil mechanics in several important aspects continues to be developed, and experience of soil surveys undertaken in conjunction with the Ministry of Transport prior to the building of experimental roads has confirmed the view that useful and often essential information can be obtained in this way. As knowledge of subsoil conditions accumulates, it is reasonable to expect that the value of such soil surveys, preliminary to construction, will become progressively greater. The principal addition to the equipment of the Soil Mechanies Laboratory during the year has been an apparatus for obtaining undisturbed samples of soil, which operates a sampling tool by means of a double-acting hydraulic ram. After a hole has been drilled in the ground to the required depth, the tool is lowered into position and pressed home by the 10-ton ram. Incorporated in the tool-head is a relief valve which permits air or water to be expelled. The samples are tested in a new type of consolidation machine which also has been designed and constructed at the Road Research Laboratory during the year. An illustration shows a machine of a simple lever-loading type in which the specimen is held rigidly against a steel ball, the deformation being indicated on a dial gauge. In this department of the work, standard tests are being developed and the mechanical and physical properties of soils are being investigated, particularly in relation to the shrinkage of stabilized soils and the principles of soil compaction.

As already indicated, road surfacings receive a large share of attention. The report gives further details of the system of recording progressive changes in roads by means of the recently developed surface texture prints. These, as described in NATURE of January 6, p. 40, are a form of offset prints made on sheets of paper by means of a printing roller run over a small area of the road surface.

* Report of the Road Research Laboratory. (H.M. Stationery Offlce. $38,6 d$. net.)

\section{SEVENTY YEARS AGO}

\author{
NATURE, vol. I, April 7, I870
}

Natural Science at Cambridge

WE have heard so much recently of the longdelayed determination of Cambridge University to apply itself in earnest to the cultivation of Natural Science, that the information in the following paragraph must be a blow to those of its friends who hoped to see that it was entering on a new course : "The Syndicate appointed to consider the means of raising the necessary funds for establishing a Professor and a Demonstrator of Experimental Physies, and for providing buildings and apparatus . . . have made a report to the Senate, in which they state that they have addressed a communication to the several colleges of the University, to inquire whether they would be willing . . . to make contributions from their corporate funds for the above. mentioned objects. The answers of the several colleges, except that of King's, which has not yet been received . . . indicated such a want of concurrence in any proposal to raise contributions from the corporate funds of colleges, by any kind of direct taxation, that the Syndicate felt obliged to abandon the motion. . . They confined their attention, therefore, to the means of raising sufficient funds only for carrying out the recommendations of the Physical Science Syndicate in their report dated Feb. 27, 1869. These were to provide the stipends of a Professor of Experimental Physics, of a Demonstrator and an attendant, requiring altogether a sum of $660 \mathrm{l}$. per annum ; also to provide a capital sum of $5000 \mathrm{l}$. for a new building, and $1300 \mathrm{l}$. for apparatus. The Syndicate are of opinion that these sums may be raised from the ordinary sources of revenue of the University."

\section{The Rotundity of the Earth}

A RECENT number of the Field contains an account of a very amusing investigation which has been recently conducted on the Bedford Level to settle the question whether the earth is a globe or not! It appears that a Mr. Hampden threw out a challenge by which he offered to pay $500 \mathrm{l}$. to anyone who would prove the rotundity, which challenge has been taken up by Mr. A. R. Wallace, who has lodged a similar sum with the Editor of the Field. To test this point, six miles of the Bedford Level were used, three signals, each 13 feet 4 inches above the water level, being put up three miles apart. Mr. Wallace asserted that if he were correct the central signal would appear elevated about 5 feet above the line joining the other two; Mr. Hampden holding, of course, that they would all be in the same straight line.

Although the diagrams of what was seen by the telescopes used at both ends, and acknowledged to be correct by Mr. Hampden and his associate, show the central signal more than 5 feet above the $\operatorname{lin} \theta$ of the two extremes, "these gentlemen coolly claim the victory, and threaten to bring an action against the Editor of the Field (who was appointed umpire by $\mathrm{Mr}$. Hampden himself) for fraudently deciding against them."

We hear from Edinburgh that there is much excitement amongst the supporters of the Lady Medical Students, on account of the Professor of Chemistry refusing to accord one of the Hope Scholarships to Miss Edith Pechley, who, by the number of marks gained, is entitled to a junior scholarship. 